\title{
Downregulation of TTF1 in the rat hypothalamic ARC or AVPV nucleus inhibits Kiss 1 and GnRH expression, leading to puberty delay
}

\author{
Shaolian Zang, Xiaogin Yin and Pin Li
}

\begin{abstract}
Background: TF1 is a transcription factor that is expressed in the hypothalamus after birth and plays crucial roles in pubertal development. TFF1 may regulate the expression of the Kiss1 gene, which may drive puberty onset in the hypothalamic arcuate (ARC) and anterior ventral paraventricular (AVPV) nuclei.

Methods: A dual-luciferase reporter assay was used to detect binding between TTF1 and the Kiss1 gene promoter. To investigate the effects of TTF1, we modified TTF1 expression in cell lines and in the ARC or AVPV nucleus of 21day-old female rats via lentivirus infection. TTF1 and other puberty onset-related genes were detected by qRT-PCR and western blot analyses.

Results: The in vitro data indicated that TTF1 knockdown (KD) significantly reduced Kiss1 and GnRH expression. Overexpression (OE) of TTF1 promoted Kiss 1 expression. In vivo, the expression of Kiss 1 and GnRH decreased significantly in the rats with hypothalamic ARC- or AVPV-specific TTF1 KD. The TFF1-KD rats showed vaginal opening delay. H\&E staining revealed that the corpus luteum was obviously reduced at the early puberty and adult stages in the rats with ARC- or AVPV-specific TTF1 KD.

Conclusion: TTF1 bound to the promoter of the Kiss 1 gene and enhanced its expression. For 21-day-old female rats, decreased TTF1 in the hypothalamic ARC or AVPV nucleus resulted in delayed vaginal opening and ovarian abnormalities. These observations suggested that TFF1 regulates puberty onset by promoting the expression of Kiss 1 and plays an important role in gonad development.
\end{abstract}

Keywords: Thyroid-specific transcription factor 1 (TTF1), Kiss1, Gonadotropin-releasing hormone (GnRH), RNA interference (RNAi), Stereotaxic injection, Puberty

\section{Background}

In mammals, the maturation of reproductive function begins with the onset of puberty, a process regulated by the hypothalamic-pituitary-gonadal (HPG) axis and tightly coordinated by a complex network of excitatory and inhibitory genetic factors. The HPG axis is first

\footnotetext{
* Correspondence: lipin2019@126.com

Department of Endocrinology, Shanghai Children's Hospital, Shanghai Jiao Tong University, Shanghai 200062, People's Republic of China
}

activated during the embryonic phase and early postnatal days, and it is subsequently suppressed in childhood. However, the HPG axis is reactivated, and its activation culminates at the onset of puberty [1]. At puberty initiation, the secretion of gonadotropin-releasing hormone $(\mathrm{GnRH})$, which acts on the gonads, increases significantly in the hypothalamus, causing a surge in sex steroid hormones and leading to gonadal development [2]. Genetic and/or environmental factors affect the pubertal

(C) The Author(s). 2021 Open Access This article is licensed under a Creative Commons Attribution 4.0 International License, which permits use, sharing, adaptation, distribution and reproduction in any medium or format, as long as you give appropriate credit to the original author(s) and the source, provide a link to the Creative Commons licence, and indicate if changes were made. The images or other third party material in this article are included in the article's Creative Commons licence, unless indicated otherwise in a credit line to the material. If material is not included in the article's Creative Commons licence and your intended use is not permitted by statutory regulation or exceeds the permitted use, you will need to obtain permission directly from the copyright holder. To view a copy of this licence, visit http://creativecommons.org/licenses/by/4.0/ The Creative Commons Public Domain Dedication waiver (http://creativecommons.org/publicdomain/zero/1.0/) applies to the data made available in this article, unless otherwise stated in a credit line to the data. 
development time of mammals. Using epidemiological information, previous researchers determined that 50 $80 \%$ of abnormal adolescent development time was associated with genetic factors [3]. However, the regulatory mechanism of GnRH neurons is very complicated, and the specific molecular mechanism is not fully understood. It is currently agreed that Kisspeptin and its receptor G protein-coupled receptor 54 (GPR54) directly regulate the release of GnRH. Kisspeptin is a key upstream regulator of $\mathrm{GnRH}$ and pubertal development [4-6]. The arcuate (ARC) and anterior ventral paraventricular (AVPV) nuclei are well known for their abundant expression of the Kiss1 gene [7]. Large numbers of studies have suggested that these two regions have different effects on reproduction. The ARC is negatively regulated by oestrogen. It is responsible for the pulsed release of luteinizing hormone (LH) to form the reproductive cycle, while the AVPV is positively regulated by oestrogen and is responsible for the generation of the preovulatory LH surge that stimulates ovulation $[8,9]$. Consistent with these studies, oestradiol-mediated positive feedback increases the excitability of these neurons and glutamate transmission to AVPV neurons [10]. In fact, oestrogen receptor $\alpha(E R \alpha)$ expression on Kiss1positive neurons is critical for the positive or negative feedback of oestradiol because Kisspeptin-specific ER $\alpha$ knockout (KERKO) mice were shown to exhibit highfrequency LH pulses and did not exhibit an oestradiolinduced LH surge [9]. Moreover, the expression of Kisspeptin in the region around the third ventricle $(3 \mathrm{~V})$ is sex biased, and the number of Kiss1-expressing neurons in females is much greater than that in males. Researchers hypothesized that this was necessary for the LH surge before ovulation [11-13].

Thyroid-specific transcription factor-1 (TTF-1), also known as Nkx2-1, thyroid-specific enhancer-binding protein (T/EBP) or TITF1, is located on chromosome $14 \mathrm{q} 13.3$ and contains three exons. The TTF1 protein, which consists of 371 amino acids, is a $38-\mathrm{kDa}$ nuclear DNA-binding protein $[14,15]$. Previous studies found that the amino acid sequence of TTF1 has $98 \%$ similarity among the human, rat and mouse genomes and that the 60-amino acid homology domain is highly conserved [16]. TTF1 is mainly expressed in the forebrain, pituitary gland, lung and thyroid [17]. In recent years, studies have shown that TTF1 may be an upstream regulator of the Kiss1 gene [18]. Researchers have found that the ventromedial nucleus and dorsal nucleus of the hypothalamus did not develop in mice carrying a TTF1 gene null mutation, causing the wall of the third ventricle to fuse on its ventral side and resulting in the absence of the ARC [17]. Correa et al. [19] found that conditional knockout of TTF1 in the ventromedial hypothalamus interfered with the normal development of neurons in the central nervous system. TTF1 is critical for functional hypothalamic and pituitary morphology in mammals. Moreover, researchers found that when the secretion of sex hormones was at the basal level, the level of TTF1 mRNA in the hypothalamus increased during development [20]. Kim et al. [20] found that the expression of TTF1 reached a significant peak before puberty onset between postnatal days 26 and 27. These results demonstrated that TTF1 is a central component of the puberty process that might be involved in the central activation of mammalian adolescence.

The purpose of this study was to investigate the probable effects of TTF1. Our study aimed to clarify the potential mechanism and phenotype resulting from TTF1 gene downregulation in the rat hypothalamus and ND723 neuron cell lines or TTF1 gene upregulation in GT17 cells. This research will help us understand the initial process of puberty.

\section{Materials and methods Animals}

Twenty-one-day-old female Sprague-Dawley (SD) rats (body weight, $50-60 \mathrm{~g})(n=114)$ were purchased from Shanghai SLAC Laboratory Animal Co. (Shanghai, China) and randomly separated into four groups: injection of lentivirus-enhanced green fluorescent protein (LV-EGFP) in the ARC, injection of LV-EGFP in the AVPV, injection of LV-TTF1-shRNA in the ARC and injection of LV-TTF1-shRNA in the AVPV. The rats were subjected to bilateral microinjections between 12:00 and 18:00. Then, they were housed five per cage under controlled temperature $\left(21 \pm 2{ }^{\circ} \mathrm{C}\right)$ and humidity $(55 \pm 10 \%)$ conditions with a $12 \mathrm{~h}$ light $/ 12 \mathrm{~h}$ dark cycle (lights on between hours 7:00-19:00). Food and water were available ad libitum. We inspected the vaginal openings of the rats every morning between 9:00 and 9:30 AM daily from postnatal day 28 (PND28). Finally, the rats were euthanized at the juvenile (PND25), early puberty (PND35), and adult stages (PND42) between 9:00 and 17:00. All procedures were approved by the Institutional Animal Care and Use Committee of Shanghai, China (Ethics review number: 2018022).

\section{Cell culture}

ND7-23 is a neuronal cell line that endogenously expresses not only the TTF1 gene but also the Kiss1 and GnRH genes. It was used to verify the knockdown efficiency of the lentivirus. ND7-23 and $293 \mathrm{~T}$ cells were purchased from the Cell Bank of the Chinese Academy of Sciences (Shanghai, China). GT1-7 is a hypothalamic neuronal cell line. The GT1-7 cells used in this study were kindly provided by the Shanghai Clinical Center for Endocrine and Metabolic Diseases, Shanghai Jiaotong University. The cells were maintained in Dulbecco's 
modified Eagle's medium (DMEM, Gibco, NY, USA) supplemented with $10 \%$ foetal bovine serum (FBS, Gibco), $100 \mathrm{U} / \mathrm{mL}$ penicillin and $100 \mu \mathrm{g} / \mathrm{mL}$ streptomycin. The cells were cultured in a humidified atmosphere containing $5 \% \mathrm{CO}_{2}$ at $37^{\circ} \mathrm{C}$.

\section{TTF1 shRNA construction}

All oligo sequences were designed with an online design tool provided by Invitrogen (http://www.invitrogen.com/ rnai). The oligo sequences of the rat TTF1 shRNA are shown in Table 1. Additionally, we constructed a TTF1 overexpression plasmid (NM_013093.1). A restriction enzyme site and a Kozak sequence (GCCACC) were added to the $5^{\prime}$ end of the sequence. The oligonucleotides were used to construct plasmid vectors. A schematic diagram of the vector construction is shown in Fig. 1. After correct identification, the recombinant plasmid was amplified in large amounts. Fluorescence immunochemistry was used to determine the transfection efficiency. qRT-PCR and western blotting were applied to detect the interference efficiency of TTF1-shRNA.

\section{Lentivirus infection}

The ability of the TTF1-shRNA constructs to reduce TTF1 levels was measured and compared to that of the negative control lentivirus (LV-NC) in the ND7-23 cell line. The cells were plated in 6 -well plates at $2 \times 10^{5}$ cells per well in 10\% FBS. Twenty-four hours later, the cells were transduced with the viruses. Seventy-two hours after transfection, total RNA and protein were extracted from the ND7-23 cells to detect the interference efficiency of the TTF1-shRNAs. Additionally, we used the above methods to transfect GT1-7 cells with the TTF1 overexpression plasmids to explore the regulatory relationship between TTF1 and Kiss1.

\section{Bilateral microinjection}

As described in a previous study [21, 22], surgery was performed at PND21 to allow $72 \mathrm{~h}$ of infection for maximum expression of TTF1-shRNA before puberty onset. Twenty-one-day-old female rats were positioned in a stereotaxic instrument after they were deeply anaesthetized with $1 \%$ sodium pentobarbital $(0.5 \mathrm{~mL} / 100 \mathrm{~g}$ body weight). The skin and periosteum were incised to expose the bregma point. At the beginning of the experiment, $0.5 \mu \mathrm{L}$ of Brilliant Blue was injected into the ARC or AVPV nucleus to visualize the position of the nuclei in each animal. Two microlitres of TTF1-shRNA or LVEGFP lentivirus $\left(1.8 \times 10^{9}\right.$ transducing units $\left.[\mathrm{TU}] / \mathrm{mL}\right)$ was microinjected bilaterally into the ARC and AVPV nuclei using a $10-\mu \mathrm{L}$ syringe (Gauge, China) with a glass needle connected to its tip. After injection, we left the needle in place for 5-10 min and then removed it slowly. The coordinates for the ARC $(0.4 \mathrm{~mm}$ lateral, $1.6 \mathrm{~mm}$ posterior to bregma, $9.4 \mathrm{~mm}$ below the surface of the dura) and AVPV $(0.2 \mathrm{~mm}$ lateral, $1.2 \mathrm{~mm}$ anterior to bregma, $8.0 \mathrm{~mm}$ below the surface of the dura) were determined from the Rat Brain Atlas (Paxinos and Watson, Fifth Edition) and were used previously [23, 24].

\section{Tissue preparation}

Rats were weighed and delivered a fatal dose of $3 \%$ sodium pentobarbital (Sigma, USA) to induce euthanasia. The anogenital distance (AGD) of the rats was measured with a Vernier calliper. The rats were decapitated to collect the whole brain, which was subsequently frozen on dry ice. The hypothalamic tissues containing the AVPV and ARC nuclei were separated and immediately placed into liquid nitrogen. The samples were stored at $-80^{\circ} \mathrm{C}$ and used for qRT-PCR (TaKaRa, Japan) and western blotting. The uterine and ovarian tissues were collected and weighed to calculate the uterine and ovarian organ coefficients. For immunofluorescence localization, we perfused saline with $10 \%$ formalin through the hearts of rats. Intact brains were removed from the skulls and stored in $10 \%$ formalin overnight at $4{ }^{\circ} \mathrm{C}$. The brains were transferred into 20 and $30 \%$ sucrose when they were totally settled. Serial $20-\mu \mathrm{m}$ coronal sections containing the AVPV or ARC were obtained using a freezing microtome (Thermo, MI, USA).

\section{Quantitative real-time PCR (qRT-PCR)}

Total RNA was extracted from the tissues (ARC or AVPV) and cultured cells using TRIzol Reagent (Invitrogen, CA, USA) following the manufacturer's instructions. The RNA concentrations were determined by spectrophotometric traces (Nanodrop, Thermo, Wilmington, DE). Total RNA $(1 \mu \mathrm{g})$ was transcribed into cDNA in a volume of $20 \mu \mathrm{L}$ using 5X PrimeScript RT Master Mix (TaKaRa, Japan). We measured the mRNAs of interest using the SYBR Premix Ex Taq qPCR system (TaKaRa, Japan). The primers (Table 2) were synthesized by Shanghai Sangon Biotech Co., Ltd., and $\beta$-actin was used as an internal reference. All PCRs were carried out using

Table 1 Sequences of the shRNA oligos targeting rat TFF1 and the negative control oligos

\begin{tabular}{ll}
\hline Name & Sequences(5')-3') \\
\hline TTF1-shRNA-F & CACCGGAGGAAAGCTACAAGAAAGTCGAAACTTTCTTGTAGCTTTCCTCC \\
TTF1-shRNA-R & AAAAGGAGGAAAGCTACAAGAAAGTTCGACTTCTTGTAGCTTTCCTCC \\
Negative control & CTAAGGTTAAGTCGCCCTCGC \\
\hline
\end{tabular}




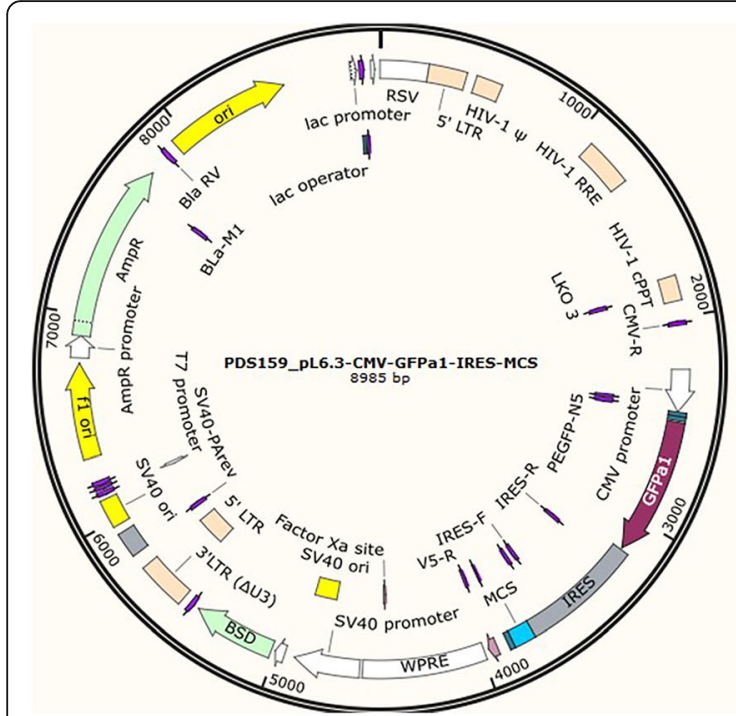

Fig. 1 Lentivirus vector profile

a Roche Real-Time PCR System in a total reaction volume of $10 \mu \mathrm{L}$ containing $3 \mu \mathrm{L}$ of cDNA $(50-100 \mathrm{ng} / \mu \mathrm{L})$, $2 \mu \mathrm{L}$ of primers ( $1 \mu \mathrm{L}$ of each primer), and $5 \mu \mathrm{L}$ of SYBR Premix Ex Taq. The PCR conditions were as follows: initial denaturation and enzyme activation at $95^{\circ} \mathrm{C}$ for 600 s, followed by 45 cycles of denaturation at $95^{\circ} \mathrm{C}$ for $10 \mathrm{~s}$, annealing at $60^{\circ} \mathrm{C}$ for $30 \mathrm{~s}$, and extension at $72^{\circ} \mathrm{C}$ for 1 min. All samples were run in triplicate for each gene. The relative expression of genes was determined using the $2^{-\Delta \Delta C t}$ method with normalization to $\beta$-actin expression.

\section{Western blotting}

Samples were homogenized in M-PER $^{\circ}$ Mammalian Protein Extraction Reagent lysis buffer (Thermo, MI, USA) containing protease inhibitor cocktail and $0.5 \mathrm{M}$ EDTA (Thermo, MI, USA) (1:100 dilution). The supernatant was collected after centrifugation at $12000 \mathrm{rpm}$ for $30 \mathrm{~min}$ at $4{ }^{\circ} \mathrm{C}$. The protein concentration was determined using the BCA Protein Assay Kit (Thermo, MI, USA). The protein samples were separated using sodium dodecyl sulfate-polyacrylamide gel electrophoresis (SDSPAGE) and then transferred onto polyvinylidene fluoride (PVDF) membranes (Millipore, MA, USA). The membranes were blocked with $5 \%$ nonfat milk at room temperature for $1 \mathrm{~h}$ and then incubated with anti-TTF1 (1:500, Abcam, MA, USA), anti-Kiss1 (1:400, Abcam, MA, USA) or anti- $\beta$-tubulin antibody (1:1000, CST, MA, USA) at $4{ }^{\circ} \mathrm{C}$ overnight. Subsequently, the membranes were rinsed three times with Tris-buffered saline with $0.1 \%$ Tween 20 (TBST) every $10 \mathrm{~min}$ and probed with an HRP-labelled secondary antibody (1:10000, Jackson, PA, USA) at room temperature for $1 \mathrm{~h}$. After three additional rinses with TBST, the membranes were visualized using the ECL system. The grey values of the protein bands were analysed using ImageJ software.

\section{Haematoxylin-eosin (H\&E) staining}

Rat ovaries were collected and fixed in $10 \%$ neutralbuffered formalin. Subsequently, they were dehydrated in a series of ethanol concentrations, cleared in xylene, blocked in paraffin wax, and cut into serial $4 \mu \mathrm{m}$

Table 2 Primers used for qRT-PCR

\begin{tabular}{|c|c|c|}
\hline Gene & Forward primers $\left(5^{\prime}-3^{\prime}\right)$ & Reverse primers $\left(5^{\prime}-3^{\prime}\right)$ \\
\hline Kiss1 (Rat) & AGCTGCTGCTTCTCCTCTGT & AGGCTTGCTCTCTGCATACC \\
\hline TTF1 (Rat) & GGACGTGAGCAAGAACATGG & GCCGACAGGTACTTCTGCTG \\
\hline GnRH (Rat) & CCGCTGTTGTTCTGTTGACTGTG & GGGGTTCTGCCATTTGATCCTC \\
\hline$\beta$-actin (Rat) & TGCCGCATCCTCTTCCT & GGTCTITACGGATGTCAACG \\
\hline TTF1 (mouse) & GGGCCAGGTCTCTAGCCTATC & CTCACCAGGTCCGACCATAAA \\
\hline Kiss1 (mouse) & CTCTGTGTCGCCACCTATGG & AGGCTTGCTCTCTGCATACC \\
\hline GnRH (mouse) & TGATCCTCAAACTGATGGCCG & CGCAACCCATAGGACCAGTG \\
\hline$\beta$-actin (mouse) & AAGATCAAGATCATTGCTCCTCC & GACTCATCGTACTCCTGCTTGC \\
\hline
\end{tabular}


sections. Six representative sections were selected from each ovary; these were deparaffinized in xylene, hydrated in a series of ethanol concentrations, and stained with H\&E. Finally, the sections were analysed under an optical microscope.

\section{Dual-luciferase reporter assay}

The JASPAR database was used to identify the binding site between TTF1 and the Kiss1 promoter. A Kiss1-promoter luciferase plasmid and an empty plasmid (pGL4.10) were constructed. Two hundred ninety-three $\mathrm{T}$ cells were seeded at a cell density of $2 \times 10^{5} /$ cells $\mathrm{mL}$. They were divided into four groups: the Kiss1-promoter $+\mathrm{NC}$ group, the Kiss1-promoter + TTF1-OE group, the pGL4.10 + NC group, and the pGL4.10+ TTF1-OE group. Lipofectamine 2000 (Invitrogen, CA, USA) was used to transfect the Kiss1 promoter plasmid and the Renilla luciferase-containing plasmid. The activity of firefly luciferase relative to that of Renilla luciferase was determined using the Dual-Luciferase Reporter Assay Kit (Vazyme, China).

\section{Statistics}

All statistical analyses were performed using SPSS software (version 13; SPSS, Inc., Chicago IL, USA). The data are presented as the mean \pm S.E.M. The data were first subjected to normality and equal variance tests. The data that passed these two tests were then analysed by Student's t-test to compare two groups using SPSS. The intergroup differences among multiple groups were analysed using one-way analysis of variance (ANOVA). Then, we plotted the data with GraphPad Prism 8.0 software (GraphPad, San Diego, CA, USA). $P<0.05$ was regarded as statistically significant.

\section{Results}

TTF1 knockdown inhibited the expression of Kiss1 and GnRH in ND7-23 cells.

We successfully designed RNA interference sequences for the rat TTF1 gene and inserted them into a lentiviral vector. After infection for $72 \mathrm{~h}$, enhanced green fluorescent protein (EGFP) was expressed in ND7-23 cells (Fig. 2a). qRT-PCR and western blot analysis showed that LV-TTF1-shRNA transfection significantly decreased the expression of the TTF1 gene (Fig. $2 \mathrm{~b}$ and c). TTF1 knockdown reduced the mRNA levels of Kiss1 and $\mathrm{GnRH}$ (Fig. 2b). A dual-luciferase reporter assay demonstrated that TTF1 could bind to the promoter of the Kiss1 gene (Fig. 2d). These findings indicated that TTF1 could bind to the Kiss 1 promoter and activate the transcription of the Kiss1 gene.

\section{Overexpression of TTF1 promoted the expression of Kiss 1} in GT1-7 cells

We transfected GT1-7 cells with a TTF1 overexpression plasmid to explore the regulatory relationship between TTF1 and Kiss1. After infection for $72 \mathrm{~h}$, EGFP was expressed in GT1-7 cells (Fig. 3a). qRT-PCR showed that transfection of the TTF1 overexpression plasmid significantly increased the expression of the TTF1 and Kiss1 genes (Fig. 3b and c). However, the expression of GnRH mRNA decreased (Fig. 3b). These results suggested that TTF1 promoted Kiss1 expression in GT1-7 cells.

\section{Anatomical localization of EGFP in the ARC and AVPV}

LV-TTF1-shRNA was injected into the ARC or AVPV nucleus of 21-day-old female rats via bilateral microinjection, and rats injected with LV-NC were used as a negative control. We referred to the Rat Brain Atlas (Paxinos and Watson, Fifth Edition). We first injected $1 \mu \mathrm{L}$ of lentivirus into the ARC and AVPV of 21-day-old female rats. After injection, little GFP expression was observed in frozen brain sections. We speculated that the lentivirus did not reach the titre that was reached in the study we referenced [25]. Then, we increased the lentivirus injection volume to $2 \mu \mathrm{L}$. EGFP-containing cell bodies and axons were observed at high densities within the ARC (Fig. 4a and c) and AVPV (Fig. 4e and g). Slight expression of EGFP was also observed in the ventromedial preoptic nucleus (VMPO), which has low expression of Kiss1 and GnRH. Critically, for the intra-AVPV and intra-ARC LV-EGFP-injected animals, no EGFPcontaining neurons were observed in the corresponding AVPV (Fig. 4b and d) and ARC (Fig. 4f and h), respectively.

\section{TTF1 knockdown reduced the expression of Kiss 1 and $\mathrm{GnRH}$ in female rats}

To determine whether TTF1 knockdown in the ARC or AVPV nucleus could influence the expression of Kiss 1 and $G n R H$, as demonstrated in vitro, we injected virus particles into 21-day-old female rats and collected ARC and AVPV tissue at PND25, PND35 and PND42 for mRNA quantitation and protein detection. The expression of the TTF1 mRNA was reduced significantly in the ARC and AVPV knockdown groups (Fig. 5a and d). TTF1 protein expression decreased significantly in the ARC and AVPV knockdown groups at PND25, PND35 and PND42 (Fig. 5g, h and i). Consistent with the in vitro data, TTF1 knockdown (TTF1-KD) in the ARC caused a pronounced reduction in Kiss1 and GnRH mRNA abundance (Fig. 5b and c). Downregulation of TTF1 in the hypothalamic AVPV also reduced Kiss1 and GnRH expression at PND25, PND35, and PND42 (Fig. $5 \mathrm{e}$ and $\mathrm{f}$ ). However, there were no significant changes in 


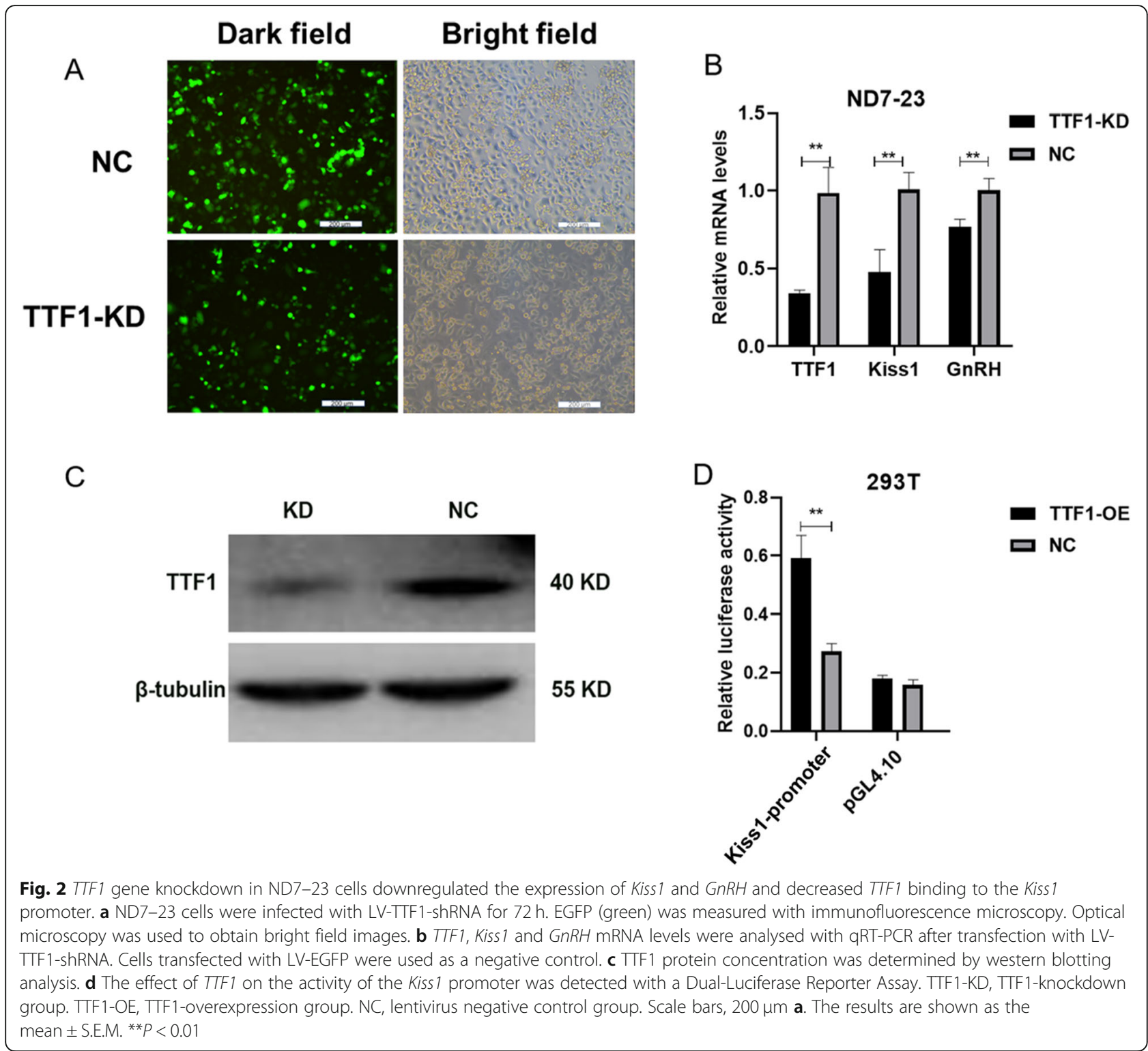

Kiss1 protein expression in the juvenile TTF1-KD groups (PND25) (Fig. 5g). We noticed that Kiss1 expression was reduced in the TTF1-KD groups at the early puberty stage (PND35) and the adult stage (PND42) (Fig. 5h and i). Decreasing TTF1 expression in the ARC and AVPV during prepuberty selectively reduced Kiss 1 and $G n R H$ expression.

TTF1 knockdown in the ARC or AVPV nucleus caused delayed puberty in female rats

TTF1-KD female rats were observed every morning after virus injection to determine the vaginal opening (VO) time. There was no significant difference in anogenital distance, ovarian organ coefficient (ovary weight/body weight), uterine organ coefficient (uterine weight/body weight), or gross body weight (Fig. 6a, b, c, d, e, f and i).
However, the rats with TTF1-KD in the AVPV $(n=11)$ showed a significant delay in the age of vaginal opening compared with that of the negative control rats $(n=7)$ (Fig. 6h). The rats with TTF1-KD in the ARC $(n=9)$ also showed a significant VO delay (Fig. 6j). The TTF1-KD groups showed a trend of decreased body weight at the prepuberty stage compared to those of the control groups (Fig. 6g). These data demonstrated that in vivo TTF1 knockdown in the ARC or AVPV nucleus led to delayed initiation of puberty and delayed the normal pubertal process.

\section{TTF1 knockdown caused abnormal ovary development in} female rats

TTF1 regulated the onset of puberty and reproduction. We used H\&E staining to observe ovarian morphology 


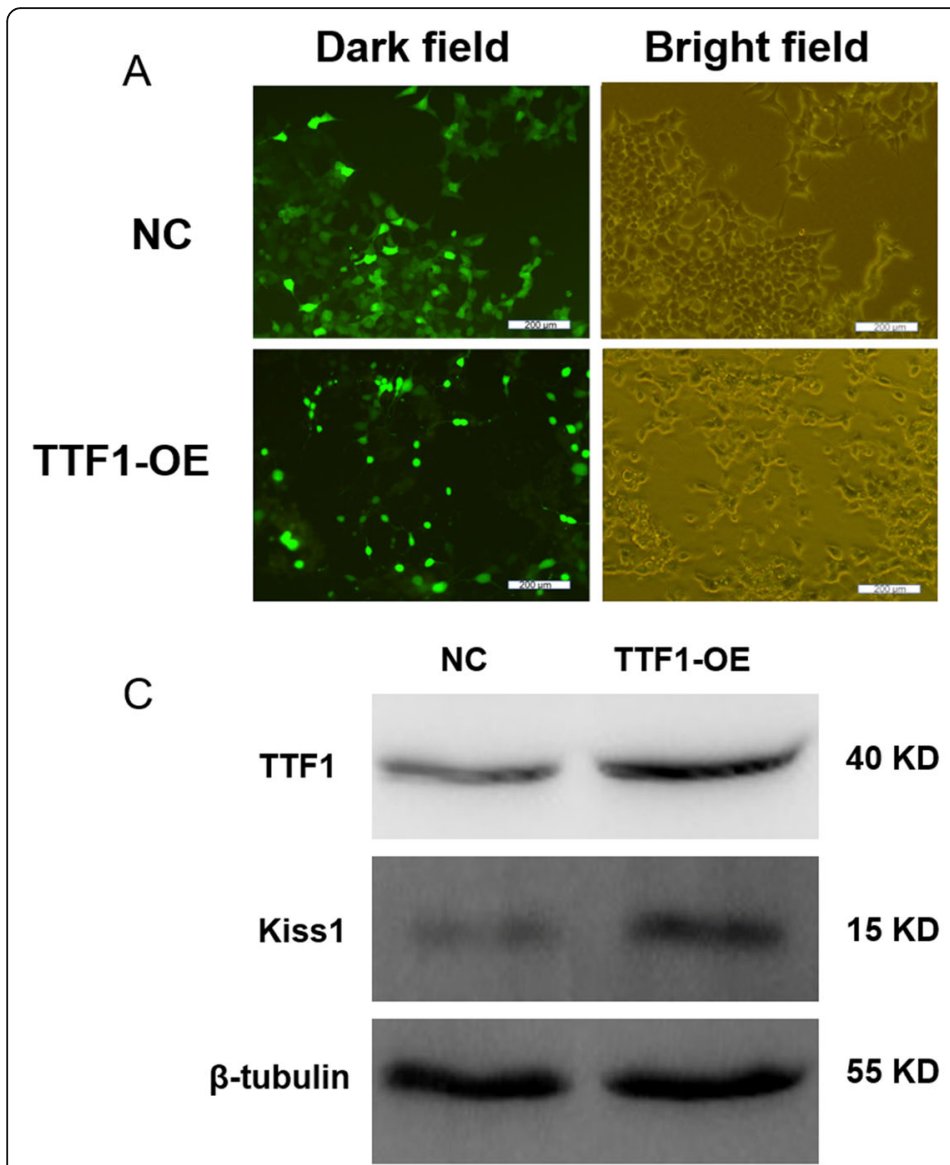

Fig. 3 TTF1 gene overexpression in GT1-7 cells promoted the expression of Kiss1. GT1-7 cells were infected with TTF1 overexpression plasmids for $72 \mathrm{~h}$. a EGFP (green) was measured with immunofluorescence microscopy. Optical microscopy was used to obtain bright field images. b TTF1, Kiss1 and GnRH mRNA levels were analysed with qRT-PCR after transfection. Cells transfected with LV-EGFP were used as a negative control. c TTF1 and Kiss1 protein concentrations were determined by western blotting analysis. TTF1-OE, TTF1-overexpression group. NC, lentivirus negative control group. Scale bars, $200 \mu \mathrm{m}$ a. The results are shown as the mean \pm S.E.M. ${ }^{* * *} P<0.001$

and function. At PND35 and PND42, the CL numbers decreased significantly in both the AVPV- and ARCspecific TTF1-KD groups compared with the negative control groups (Fig. 7a-d). These data demonstrated that in vivo silencing of TTF1 in the ARC or AVPV nucleus influenced the development of the ovary and decreased CL numbers.

\section{Discussion}

Pubertal development is a complex process of biological regulation that is affected by many factors. This research aimed to explore whether TTF1 knockdown in the ARC or AVPV nucleus via bilateral virus microinjection influences rat pubertal development and reproductive function. In in vitro experiments, we used a dual-luciferase reporter assay to detect binding between TTF1 and the Kiss1 gene promoter, not the Kiss1 receptor (Kiss1R). TTF1 bound to the Kiss 1 promoter and activated the transcription of the Kiss 1 gene. Interestingly, the expression of GnRH mRNA decreased significantly after the
B

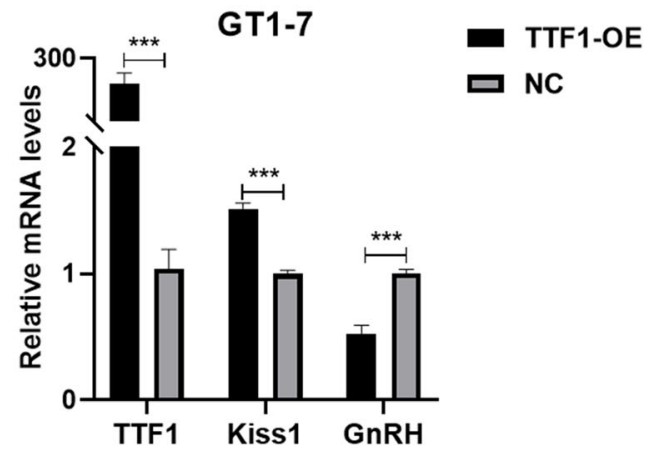

overexpression of TTF1 in GT1-7 cells. Provenzano et al. [26] found that TTF1 interfered with GnRH secretion by directly regulating Secreted Protein Acidic and Rich in Cysteine (Sparc) by binding to its promoter not directly through Kiss1 in GT1-7 cells. There are other regulatory pathways linking TTF1 and GnRH. This may explain why the expression of $G n R H$ decreased after the upregulation of TTF1 in GT1-7 cells. The relationship between TTF1 and GnRH can be explored in future studies.

Previous studies by our group found that the mRNA expression of GnRH in the ARC and AVPV continued to rise with puberty and reached a peak in the adult stage (PND42). However, the mRNA expression of Kiss1 in the ARC and AVPV reached its peak in the early puberty stage (PND35) and remained at a high level at PND42. Furthermore, after the peak expression during juvenile development, TTF1 expression decreased at the early puberty stage, and its expression increased again in the adult hypothalamus [27]. To observe the regulatory role 
A
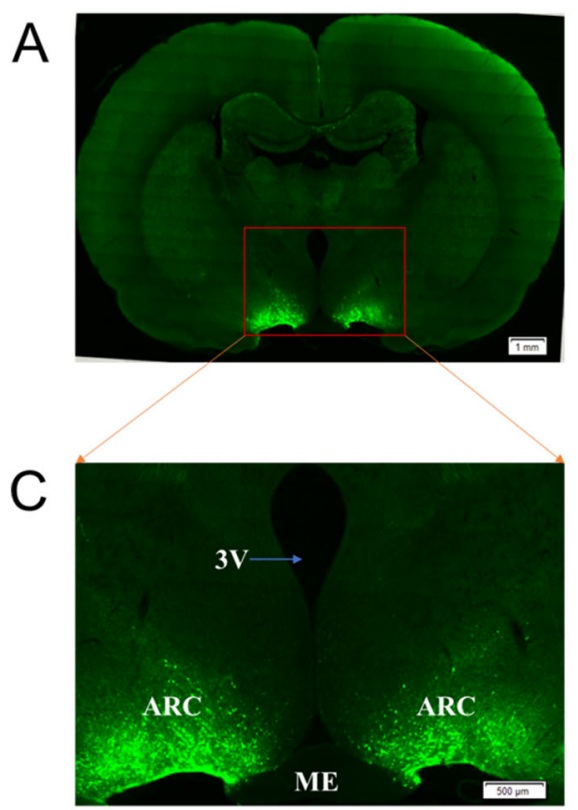

E
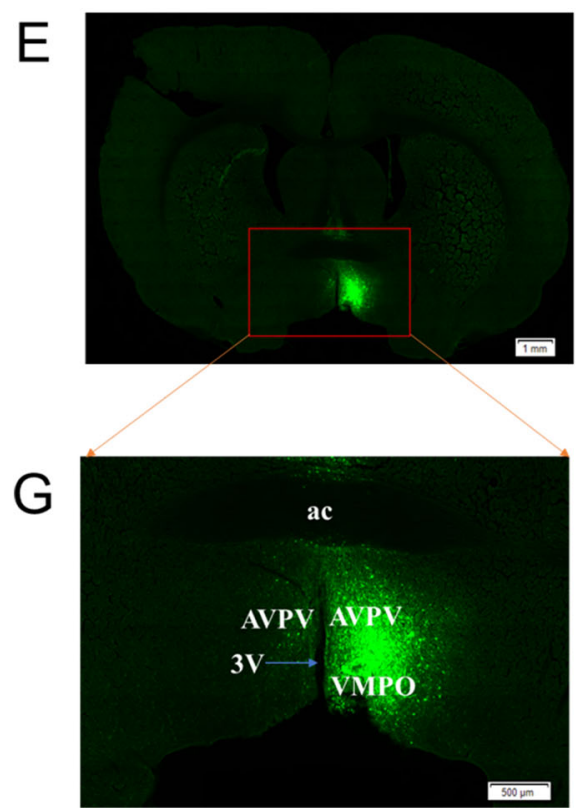

B

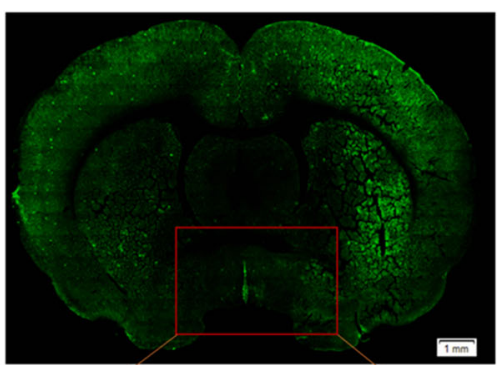

D

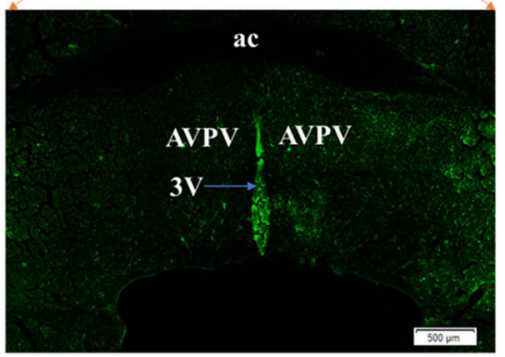

F

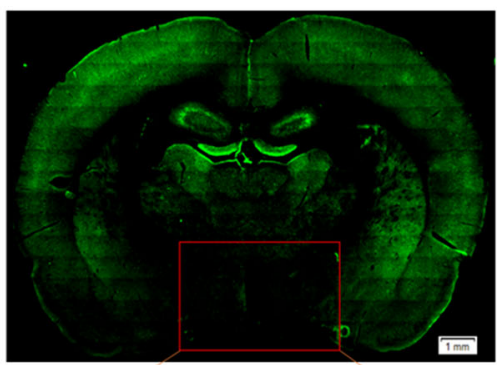

$\mathrm{H}$

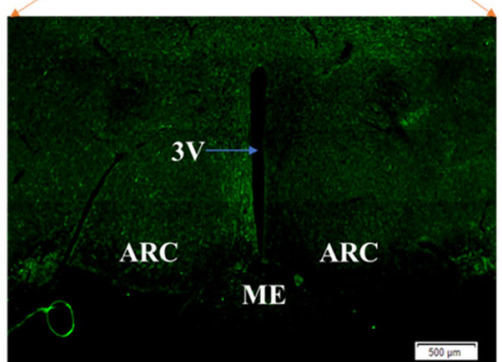

Fig. 4 Localization of GFP expression in the rat ARC and AVPV. Neuroendocrine cells are shown by GFP-staining (green). Representative images showing GFP distribution in the ARC $\mathbf{a}$ and $\mathbf{c}$ and AVPV $\mathbf{b}$ and $\mathbf{d}$ after intra-ARC administration are shown. Representative images showing GFP distribution in the AVPV $\mathbf{e}$ and $\mathbf{g}$ ) and ARC $\mathbf{f}$ and $\mathbf{h}$ after intra-AVPV administration are also shown. ARC, Arcuate nucleus. AVPV, Anterior ventral paraventricular nucleus. Three $\mathrm{V}$, the third ventricle. ac, anterior commissure. VMPO, ventromedial preoptic nucleus. ME, Medial eminence. The red arrows represent the corresponding images at high magnification. The blue arrow refers to the $3 \mathrm{~V}$. Scale bars, $1 \mathrm{~mm} \mathbf{a}, \mathbf{b}$, e and $\mathbf{f}$ ). Scale bars, $500 \mu \mathrm{m}(\mathbf{c}, \mathbf{d}, \mathbf{g}$ and $\mathbf{f}$

of TTF1 in animals, we used stereotactic injection to deliver lentivirus bearing TTF1-shRNA into the ARC or AVPV nucleus of female rats at PND21. Stereotactic injection can deliver lentivirus into mammals to induce stable and continuous expression of the target fragment at specific locations. Knockdown but not complete ablation of TTF1 expression in the ARC or AVPV nucleus preserved some physiological function of TTF1, and the potentially confounding effects of developmental compensation or redundancy were limited. In vivo experiments confirmed that we successfully injected LVTTF1-shRNA into the ARC or AVPV nucleus of 21-day- 


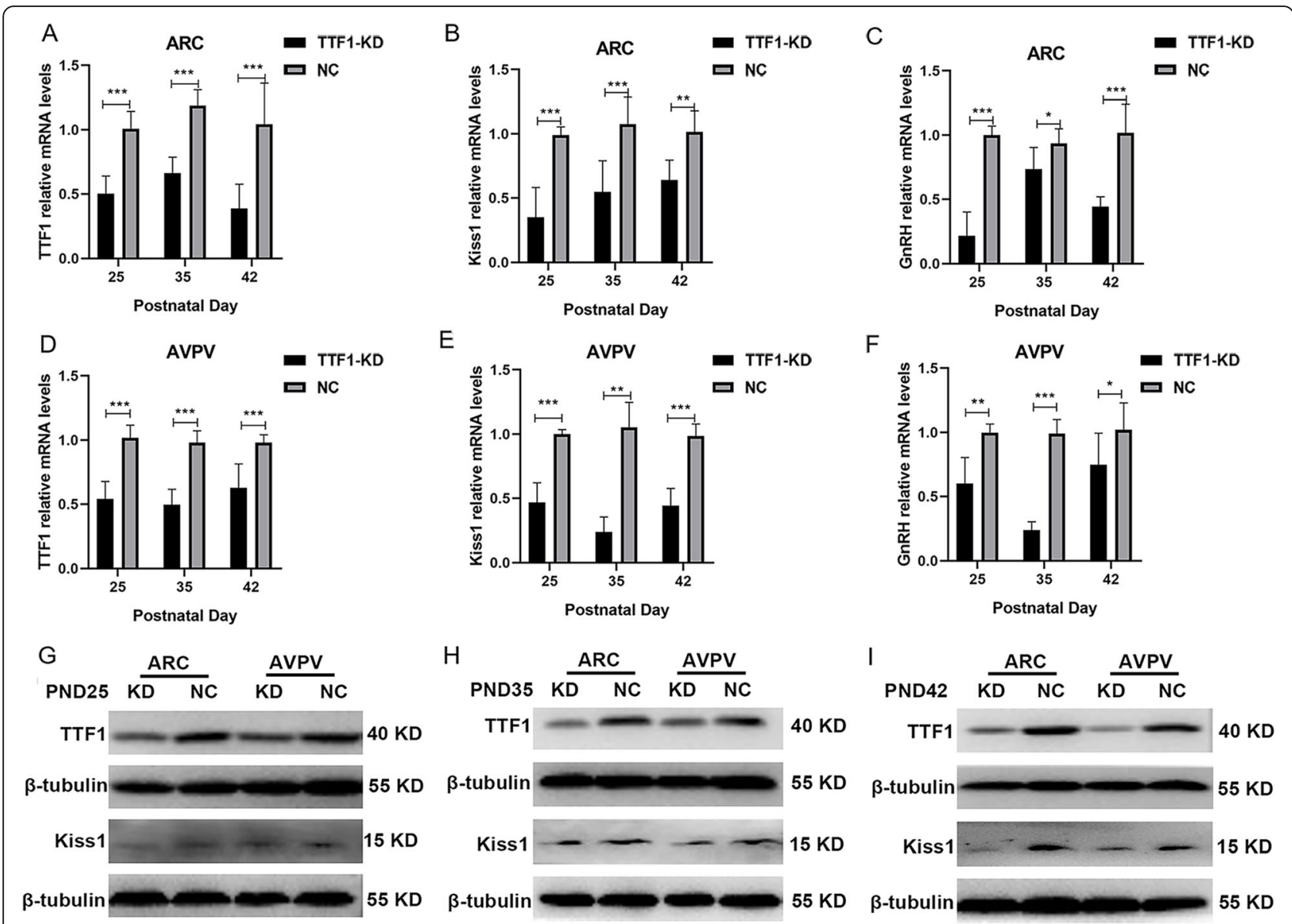

Fig. 5 Knockdown of the TTF1 gene inhibited the expression of Kiss1 and GnRH in both the ARC and AVPV. Twenty-one-day-old female rats were infected with LV-TTF1-shRNA or LV-NC $(n=6)$. a-c mRNA levels of TTF1, Kiss1 and GnRH in the ARC were detected with qRT-PCR at PND25, PND35 and PND42. $\mathbf{d}$-f Expression of the TTF1, Kiss1 and GnRH genes in the AVPV was detected with qRT-PCR $(n=6)$ at PND25, PND35 and PND42. $\beta$ actin was used as the internal reference. $\mathbf{g}$-i Expression of the TTF1 and Kiss 1 proteins in the ARC and AVPV was detected by western blotting at PND25, PND35 and PND42. KD for the TTF1-knockdown group, NC for the lentivirus negative control group. ARC, Arcuate nucleus. AVPV, Anterior ventral periventricular nucleus. The results are shown as the mean \pm S.E.M. ${ }^{*} P<0.05,{ }^{* *} P<0.01,{ }^{* * *} P<0.001$

old female rats through bilateral microinjections. Female rats that were injected with LV-TTF1-shRNA in the ARC or AVPV nucleus showed a pronounced reduction in Kiss1 and GnRH mRNA abundance. However, there were no significant changes in Kiss1 protein among the TTF1-KD group at the juvenile stage. This may be related to the low expression of Kiss1 at this stage.

Vaginal opening signifies the rising oestrogen levels necessary for puberty initiation. TTF1 gene knockdown in the ARC or AVPV nucleus delayed the day of vaginal opening. Previously, researchers found that female rats begin to enter puberty at PND32. However, in our study, the rats underwent vaginal opening earlier than in a previous study [28]. Vaginal opening began at nearly PND28 in the NC group, while vaginal opening began at nearly PND30 in the TTF1-KD group. However, we speculate that this may be related to the orthotopic injection of the nuclei performed when the rat was 21 days old. After all, this is a traumatic operation, and it may have caused vaginal opening to occur earlier than expected in all of the rats. However, there was no significant difference in the uterine organ coefficient, ovarian organ coefficient or AGD between the TTF1 knockdown and control groups. Interestingly, the rats with TTF1 knockdown in the AVPV nucleus showed decreased body weight in prepuberty compared to the control rats. The hypothalamus is the portion of the brain that serves as the centre of food intake regulation [29]. Previously, researchers found that TTF1 is mainly expressed in the ARC, ventromedial hypothalamic nucleus (VMH) and other nuclei of the hypothalamus postnatally and is closely related to feeding behaviour (food intake) [30]. Kim et al. [27] downregulated the expression of TTF1 and found a decrease in animal food intake and body weight. In 2011, they further discovered that TTF1 affects feeding behaviour via the melanocortin pathway 


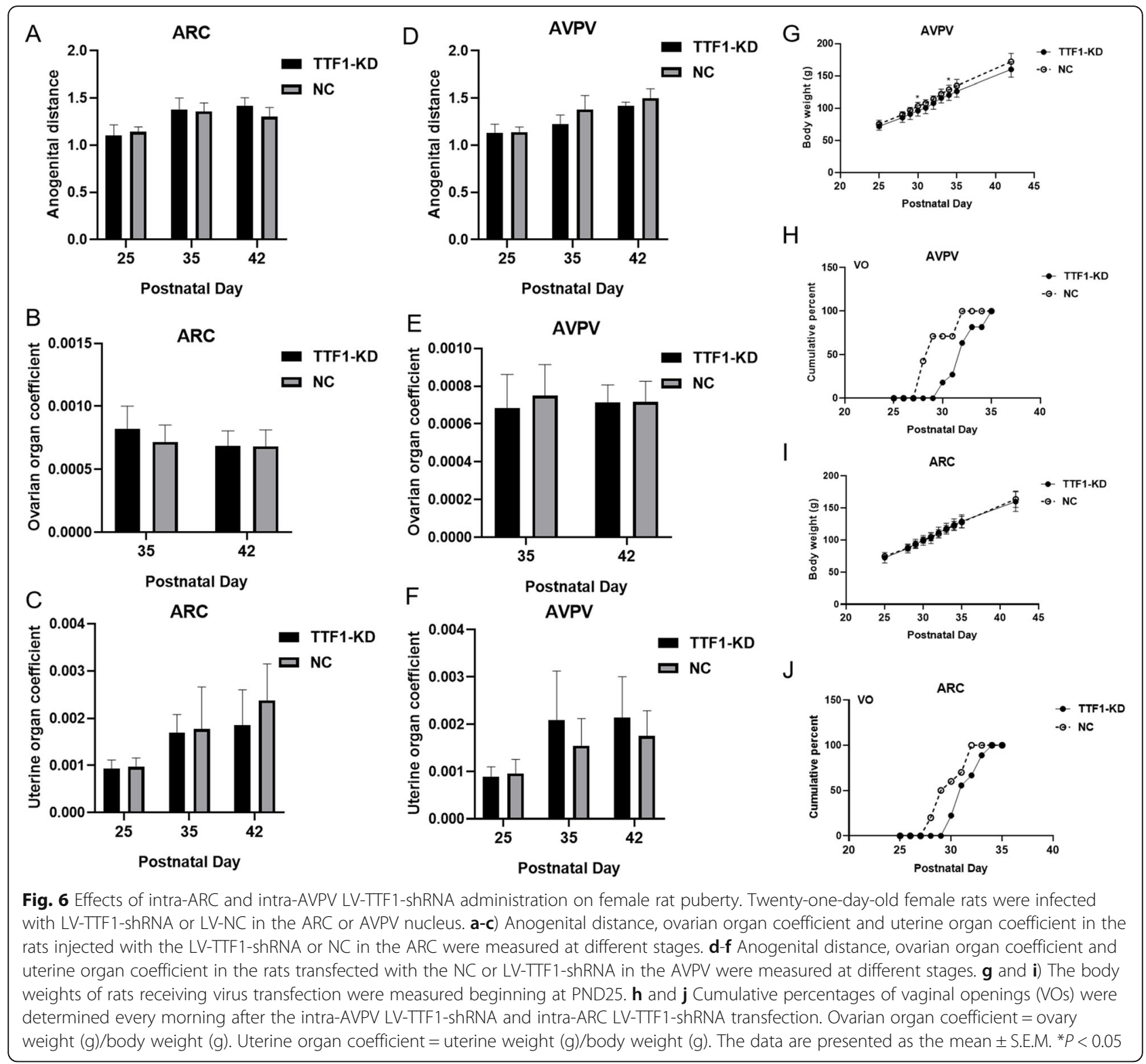

[31]. The ARC and AVPV nuclei have opposing regulatory effects on feeding behaviour [32, 33]. Moreover, these results also provide convincing support for the present results. The rats in the AVPV-specific TTF1-KD group had a tendency towards weight loss, while the weight of the rats in the ARC-specific TTF1-KD group was not significantly different from that in the control group. We hypothesize that the downregulation of TTF1 in the AVPV leads to reduced feeding behaviour and weight loss in rats. This represents a critical neural system underlying the control of body weight and other functions [34]. In summary, TTF1 has a novel role in the regulation of feeding behaviour in the rat hypothalamus.
The formation of the corpus luteum $(\mathrm{CL})$ in the ovary signifies that mammals have reproductive functions and have begun puberty. Our results suggest that pubertal development was delayed in TTF1-KD rats. Downregulation of TTF1 in the AVPV appeared to have a greater effect than downregulation of TTF1 in the ARC, whereas both TTF1-KD groups had delayed puberty and abnormal ovary development. Moreover, Mastronardi et al. [35] used Cre-loxP technology to knock out the TTF1 gene in the hypothalamus and found that mice showed delayed puberty, reduced reproductive capacity, and a short reproductive span. The present study enriches our understanding of puberty onset and provides a novel theoretical basis for the treatment of precocious puberty in children. 


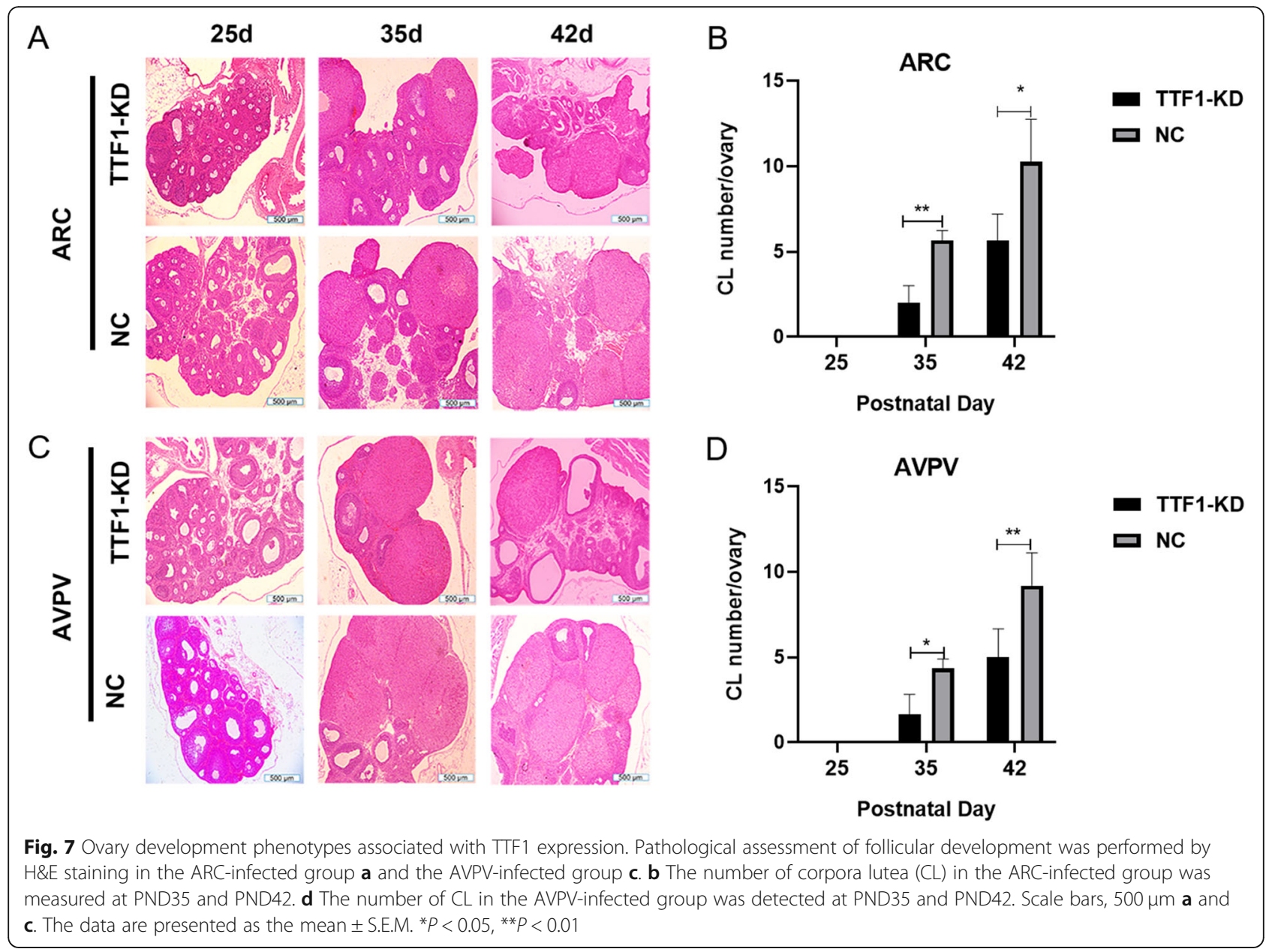

\section{Conclusions}

In vitro, TTF1 directly regulated Kiss1 expression in GT1-7 cells. In vivo, downregulation of TTF1 in ARC and AVPV female rats not only reduced Kiss 1 and GnRH expression but also resulted in delayed vaginal opening and ovarian abnormalities. In summary, we provide experimental evidence that TTF1 could control mammalian puberty onset.

\section{Abbreviations}

ARC: Arcuate; AVPV: Anterior ventral paraventricular; TTF1: Thyroid-specific transcription factor-1; T/EBP: Thyroid-specific enhancer-binding protein; GnRH: Gonadotropin-releasing hormone; KD: Knockdown;

OE: Overexpression; VO: Vaginal opening; HPG: Hypothalamic-pituitarygonadal; GPR54: G protein-coupled receptor 54; LH: Luteinizing hormone; ERa: Oestrogen receptor a; KERKO: Kisspeptin-specific ERa knockout; 3

V: Third ventricle; VMPO: ventromedial preoptic nucleus; LV-EGFP: Lentivirusenhanced green fluorescent protein; PND: Postnatal day; DMEM: Dulbecco's Modified Eagle's Medium; FBS: Foetal bovine serum; LV-NC: Lentivirusnegative control; AGD: Anogenital distance; SDS-PAGE: Sodium dodecyl sulfate-polyacrylamide gel electrophoresis; PVDF: Polyvinylidene fluoride; TBST: Tris-buffered saline with 0.1\%Tween 20; H\&E: Haematoxylin-eosin; EGFP: Enhanced green fluorescent protein; TTF1-KD: TTF1-knockdown group: TTF1-OE: TTF1-overexpression group; NC: Negative control group; CL: Corpus luteum; Ac: Anterior commissure; ME: Medial eminence; Sparc: Secreted Protein Acidic and Rich in Cysteine

\section{Acknowledgements}

We are grateful to Zhanzhuang Tian for research platform support and Jianwei Jiang for critical guidance of brain stereotaxic technology.

\section{Authors' contributions}

All authors reviewed the manuscript. Zang $S$ designed the experiments, performed the experiments and the data analysis. Li P contributed reagents/ materials/analysis tools. Yin X and Zang S drafted the manuscript and edited manuscript. All authors read and approved final version of manuscript.

\section{Funding}

This work was supported by the National Natural Science Foundation of China (81871131) and Shanghai Sailing Program (20YF1440700).

\section{Availability of data and materials}

All data generated or analysed during this study are included in this published article. The datasets used and/or analysed during the current study are available from the corresponding author upon reasonable request.

\section{Ethics approval and consent to participate}

The experimental use of these animals was approved by the Institutional Animal Care and Use Committee of Shanghai, China (Ethics review number: 2018022).

\section{Consent for publication}

All authors agree to the publication of this manuscript

\section{Competing interests}

The authors declare that they have no competitive interests. 
Received: 21 July 2020 Accepted: 12 February 2021

Published online: 23 February 2021

\section{References}

1. Abreu AP, Kaiser UB. Pubertal development and regulation. Lancet Diab Endo. 2016:4(3):254-64.

2. Ojeda SR, Roth C, Mungenast A, Heger S, Mastronardi C, Parent AS, Lomniczi A, Jung H. Neuroendocrine mechanisms controlling female puberty: new approaches, new concepts. Int J Androl. 2006;29(1):256-63.

3. Morris DH, Jones ME, Schoemaker MJ, Ashworth A, Swerdlow AJ. Familial concordance for age at menarche: analyses from the breakthrough generations study. Paediatr Perinat Ep. 2011;25(3):306-11.

4. Cortes ME, Carrera B, Rioseco H. Pablo del Rio J and vigil P: the role of Kisspeptin in the onset of puberty and in the ovulatory mechanism: a minireview. J Pediatr Adolesc Gynecol. 2015;28(5):286-91.

5. Smith JT, Clifton DK, Steiner RA. Regulation of the neuroendocrine reproductive axis by kisspeptin-GPR54 signaling. Reproduction. 2006;131(4): 623-30

6. Fergani C, Navarro VM. Expanding the role of Tachykinins in the neuroendocrine control of reproduction. Reproduction. 2016;153(1):R1-R14.

7. Tsui KH, Huang BS, Wang PH. Kisspeptin system in female reproduction: a next-generation target in the manipulation of sex hormones. J Chin Med Assoc. 2016;79(10):519-20.

8. Wang LH, Vanacker C, Burger LL, Barnes T, Shah YM, Myers MG, Moenter SM. Genetic dissection of the different roles of hypothalamic kisspeptin neurons in regulating female reproduction. Elife. 2019:8.

9. Osuka S, Iwase A, Nakahara T, Kondo M, Saito A, Bayasula, Nakamura T, Takikawa S, Goto M, Kotani T, Kikkawa F. Kisspeptin in the hypothalamus of 2 rat models of polycystic ovary syndrome. Endocrinology. 2017;158(2):367-77.

10. Wang LH, Burger LL, Greenwald-Yarnell ML, Myers MG, Moenter SM. Glutamatergic transmission to hypothalamic Kisspeptin neurons is differentially regulated by estradiol through estrogen receptor alpha in adult female mice. J Neurosci. 2018;38(5):1061-72.

11. Kinoshita M, Tsukamura $H$, Adachi $S$, Matsui $H$, Uenoyama $Y$, Iwata $K$, Yamada S, Inoue K, Ohtaki T, Matsumoto H, Maeda K. Involvement of central metastin in the regulation of preovulatory luteinizing hormone surge and estrous cyclicity in female rats. Endocrinology. 2005;146(10): 4431-6.

12. Clarkson J, d'Anglemont X, Moreno AS, Colledge WH, Herbison AE. Kisspeptin-GPR54 signaling is essential for preovulatory gonadotropinreleasing hormone neuron activation and the luteinizing hormone surge. J Neurosci. 2008;28(35):8691-7.

13. Smith JT, Li Q, Yap KS, Shahab M, Roseweir AK, Millar RP, Clarke IJ. Kisspeptin is essential for the full Preovulatory LH surge and stimulates $\mathrm{GnRH}$ release from the isolated ovine median Eminence. Endocrinology. 2011;152(3):1001-12.

14. Fernandez LP, Lopez-Marquez A, Santisteban P. Thyroid transcription factors in development, differentiation and disease. Nat Rev Endocrinol. 2015;11(1):29-42.

15. Kristensen $M H$, Nielsen $S$, Vyberg $M$. Thyroid transcription factor-1 in primary CNS tumors. Appl Immunohistochem Mol Morphol. 2011;19(5):437-43.

16. Liu J, Dong S, Li L, Wang H, Zhao J, Zhao Y. The E3 ubiquitin ligase HECW1 targets thyroid transcription factor 1 (TTF1/NKX2.1) for its degradation in the ubiquitin-proteasome system. Cell Signal. 2019;58:91-8.

17. Kimura S, Hara Y, Pineau T, Fernandez-Salguero P, Fox CH, Ward JM, Gonzalez FJ. The T/ebp null mouse: thyroid-specific enhancer-binding protein is essential for the organogenesis of the thyroid, lung, ventral forebrain, and pituitary. Genes Dev. 1996;10(1):60-9.

18. Cukier P, Wright H, Rulfs T, Silveira LFG, Teles MG, Mendonca BB, Arnhold IJP, Heger S, Latronico AC, Ojeda SR, Brito VN. Molecular and gene network analysis of thyroid transcription factor 1 (TTF1) and enhanced at puberty (EAP1) genes in patients with GnRH-dependent pubertal disorders. Horm Res Paediat. 2013;80(4):257-66.

19. Correa SM, Newstrom DW, Warne JP, Flandin P, Cheung CC, Lin-Moore AT, Pierce AA, Xu AW, Rubenstein $J$, Ingraham HA. An estrogen-responsive module in the ventromedial hypothalamus selectively drives sex-specific activity in females. Cell Rep. 2015;10(1):62-74.

20. Kim HJ, Sohn HJ, Ha M, Han JY, Kang SS, Choi WS, Cho GJ. Prepubertal chronic ethanol administration alters TTF-1 and Oct-2 expression in the hypothalamus of female rats. Mol Brain Res. 2005;136(1-2):262-6.
21. Zhou SS, Li P. Effects of NELL2 on the regulation of GnRH expression and puberty in female rats. Genet Mol Res. 2014;13(3):6672-82.

22. Li CX, Li P. Enhanced at Puberty-1 (Eap1) expression critically regulates the onset of puberty independent of hypothalamic Kiss1 expression. Cell Physiol Biochem. 2017:43(4):1402-12.

23. Bian J, Bai XM, Zhao YL, Zhang L, Liu ZJ. Lentiviral vector-mediated knockdown of Lrb in the arcuate nucleus promotes diet-induced obesity in rats. J Mol Endocrinol. 2013;51(1):27-35.

24. Hu MH, Li XF, McCausland B, Li SY, Gresham R, Kinsey-Jones JS, Gardiner JV, Sam AH, Bloom SR, Poston L, Lightman SL, Murphy KG, O'Byrne KT. Relative importance of the Arcuate and Anteroventral periventricular Kisspeptin neurons in control of puberty and reproductive function in female rats. Endocrinology. 2015;156(7):2619-31.

25. Toro CA, Wright H, Aylwin CF, Ojeda SR, Lomniczi A. Trithorax dependent changes in chromatin landscape at enhancer and promoter regions drive female puberty. Nat Commun. 2018;9(1):57.

26. Provenzano C, Pascucci B, Lupari E, Civitareale D. Large scale analysis of transcription factor TTF-1/NKX2.1 target genes in GnRH secreting cell line GT1-7. Mol Cell Endocrinol. 2010;323(2):215-23.

27. Kim JG, Nam-Goong IS, Yun CH, Jeong JK, Kim ES, Park JJ, Lee YC, Kim Yl, Lee BJ. TTF-1, a homeodomain-containing transcription factor, regulates feeding behavior in the rat hypothalamus. Biochem Biophys Res Commun. 2006;349(3):969-75.

28. Firlit MG, Schwartz NB. Uncoupling of vaginal opening and the first ovulation--an indication of an alteration in the pituitary-gonadal axis. Biol Reprod. 1977;16(4):441-4.

29. Kalra SP, Dube MG, Pu S, Xu B, Horvath TL, Kalra PS. Interacting appetiteregulating pathways in the hypothalamic regulation of body weight. Endocr Rev. 1999;20(1):68-100

30. Kaji T, Nonogaki K. Role of homeobox genes in the hypothalamic development and energy balance. Front Biosci (Landmark Ed). 2013;18:740-7.

31. Kim JG, Park BS, Yun CH, Kim HJ, Kang SS, D'Elia AV, Damante G, Lee KU, Park JW, Kim ES, Namgoong IS, Kim YI, Lee BJ. Thyroid transcription factor-1 regulates feeding behavior via melanocortin pathway in the hypothalamus. Diabetes. 2011;60(3):710-9.

32. Guan XM, Yu H, Trumbauer M, Frazier E, Van der Ploeg LHT, Chen H. Induction of neuropeptide $Y$ expression in dorsomedial hypothalamus of diet-induced obese mice. Neuroreport. 1998;9(15):3415-9.

33. Lee SJ, Kirigiti M, Lindsley SR, Loche A, Madden CJ, Morrison SF, Smith MS, Grove KL. Efferent projections of neuropeptide Y-expressing neurons of the dorsomedial hypothalamus in chronic hyperphagic models. J Comp Neurol. 2013:521(8):1891-914

34. Hill JW, Faulkner LD. The role of the Melanocortin system in metabolic disease: new developments and advances. Neuroendocrinology. 2017; 104(4):330-46.

35. Mastronardi C, Smiley GG, Raber J, Kusakabe T, Kawaguchi A, Matagne V, Dietzel A, Heger S, Mungenast AE, Cabrera R, Kimura S, Ojeda SR. Deletion of the Ttf1 gene in differentiated neurons disrupts female reproduction without impairing basal ganglia function. J Neurosci. 2006;26(51):13167-79.

\section{Publisher's Note}

Springer Nature remains neutral with regard to jurisdictional claims in published maps and institutional affiliations.

Ready to submit your research? Choose BMC and benefit from:

- fast, convenient online submission

- thorough peer review by experienced researchers in your field

- rapid publication on acceptance

- support for research data, including large and complex data types

- gold Open Access which fosters wider collaboration and increased citations

- maximum visibility for your research: over $100 \mathrm{M}$ website views per year

At $\mathrm{BMC}$, research is always in progress.

Learn more biomedcentral.com/submissions 